\title{
Community Informatics and Systems Design
}

\author{
Michael Gurstein \\ Editor-in-chief $<$ editori@,ci-journal.net $>$
}

This issue brings to Community Informatics a focused and systematic set of discussions on methods and methodology for Community Informatics practice. Not incidentally as well, the papers in this issue raise but of course don't resolve a number of the issues preparatory to broader discussions and debate concerning the role and possibilities for theory building in Community Informatics.

As well, this issue reinforces the links, sometimes forgotten in overall CI discussions, between $\mathrm{CI}$ and the practice of Information Systems. Since so much of $\mathrm{CI}$ as a practice is concerned with system implementation and thus the social (community) behaviours associated with those implementations, the necessary connection (and opportunities that go along with this) between CI and Information Systems design and development is often overlooked. This issue brings those questions immediately to the fore and provides a very rich set of questions for further research and more specifically for action research not only in system implementation but also in system design as a prelude to implementation.

Also, by highlighting $\mathrm{CI}$ in the context of design practice it changes the framework within which issues of Community Informatics theory may be articulated. Design of course, is about approximations and iterative responses to articulated or identified needs or behaviours. Design is about "best fits" and proximate models and the role for prediction or explanation from first principles is severely limited. So in many ways this special issue presents new and exciting challenges and opportunities for CI.

This is also, the second "theme" issue of the Journal and likely initiates what will be the future publishing pattern for JoCI which is an alternation between "themed" issues and "general" issues.

And finally, the reader's attention should be drawn to the proposed Code of Ethics for Community Informatics research and presumably Community Informatics practice (including design) as well. As CI comes into more general application as the basis for the local implementation of Information Systems the need for such a Code of Ethics becomes ever more acute. We can be grateful to Susan O'Donnell and Udo Averweg for having taken the initiative to develop the draft of such a Code for discussion within the CI community. 